\title{
Reversible Brainstem Auditory Evoked Potential Abnormalities in Jaundiced Gunn Rats Given Sulfonamide ${ }^{1}$
}

\author{
STEVEN M. SHAPIRO \\ Division of Child Neurology: Departments of Neurology and Pediatrics, Hedical College of I'irginia. I'irginia \\ Commonwealth University, Richmond, I'irginia 23298-(2)11
}

\begin{abstract}
Neurologic and audiologic sequelae produced by bilirubin toxicity are preventable by appropriately timed therapeutic intervention. To understand the timing and reversibility of the neural dysfunction that follows exposure to bilirubin, we recorded brainstem auditory evoked potentials (BAEP) in the Gunn rat model of bilirubin encephalopathy. Abnormal BAEP occur in jaundiced Gunn rats after injection of sulfadimethoxine (sulfa) $100 \mathrm{mg} / \mathrm{kg}$ intraperitoneally, which displaces bilirubin from blood albumin binding sites and promotes the net transfer of bilirubin into brain tissue. Reversal of BAEP abnormalities with injection of human serum albumin (ISA) $2 \mathrm{~g} / \mathrm{kg}$ intraperitoneally was studied in 17- to 20-d-old jaundiced Gunn rats. One animal from each of 14 litters was randomly assigned to one of the following treatment groups: 1) sulfa alone, 2) sulfa + HSA at $2 \mathrm{~h}, 3$ ) sulfa + HSA at $8 \mathrm{~h}$, or 4) saline alone. BAEP were recorded in each rat before and $0.1,4$, 8,24 , and $48 \mathrm{~h}$ after injection of sulfa or saline. BAEP III interwave intervals increased in all sulfa groups $(p<$ $\left.10^{-9}\right)$ to $0.27 \mathrm{~ms}(21 \%)$ above baseline at $8 \mathrm{~h}$ for the two sulfa groups not receiving treatment before that time $(p=$ 0.0002 ), but increased less for the sulfa group given ISA at $2 \mathrm{~h}$ compared with untreated animals $(p=0.02)$. Partial recovery of function occurred at 24 and $48 \mathrm{~h}$ for both HSAtreated groups compared with their 8 -h values $(p=$ 0.0001 ), and there was increased mortality at $24 \mathrm{~h}$ for the sulfa group not treated with HSA $(p<0.001)$. Amplitudes of BAEP waves I, II, and III decreased to $59 \pm 17 \%, 25$ $\pm 9 \%$, and $9 \pm 9 \%$, after sulfa; there was a protective effect of early treatment on waves I and II but not III. Amplitude of wave II but not waves I and III recovered with IISA. Thus, therapeutic intervention with ISA as late as $8 \mathrm{~h}$ after acute bilirubin encephalopathy in this animal model promotes the recovery of neurophysiologic function as effectively as intervention at $2 \mathrm{~h}$. This indicates that a hypothesized "critical period" for recovery of auditory brainstem function after acute bilirubin encephalopathy may extend beyond 8 h. (Pediatr Res 34: 629-633, 1993)
\end{abstract}

\section{Abbreviations}

BAEP, brainstem auditory evoked potential(s)

$\mathrm{jj}$, jaundiced (homozygous recessive)

ip, intraperitoneal

IWI, interwave interval(s)

Received November 11, 1992: accepted June 9, 1993.

Correspondence: Steven M. Shapiro, M.D. Box 211 M1CV Station, Richmond, VA 23298-02!1.

Supported in part by grants from the University of Wisconsin Graduate and Medical School Research Committees and by NIH Grant NIDCD ROI DC000369.

1 This research was carried out in part at the University of Wisconsin-Madison. sulfa, sulfadimethoxine

ANOVA, analysis of variance

HSA, human serum albumin

Despite advances in their care, human newborns continue to be at risk of incurring brain damage and hearing loss. Bilirubin toxicity is one potentially preventable cause of these disorders. The auditory nervous system is especially vulnerable to acute bilirubin toxicity (1). BAEP provide an extremely sensitive measure of auditory nervous system function and are abnormal in hyperbilirubinemic infants (2-6).

The significant neurologic and audiologic sequelae produced by bilirubin toxicity may be preventable by appropriately timed therapeutic intervention, and treatment for hyperbilirubinemia corrects neurophysiologic abnormalities. For example, abnormal BAEP in hyperbilirubinemic infants normalize with phototherapy or exchange transfusion $(4,6)$. However, the degree and extent of reversibility of bilirubin neurotoxicity has not been systematically explored thus far.

The Gunn rat is the classic animal model for bilirubin encephalopathy (7) and lacks the enzyme glucuronyl transferase (8), which is immature in human neonates and contributes to physiologic jaundice of the newborn. In the Gunn rat animal model, the pathologic lesions associated with bilirubin encephalopathy include damage to central auditory structures, especially the cochlear nuclei and inferior colliculi, and are similar to those found in humans (9). Changes in learning behavior (10), neurologic function (11), and BAEP (12) also parallel the human condition. Neurophysiologic abnormalities include changes in BAEP waves arising from the cochlear nuclei and more central pathways (12-15).

Bilirubin in blood normally is bound to albumin, but it can be displaced by drugs such as sulfonamides, which compete for binding sites on albumin (16). When the long-acting sulfonamide, sulfadimethoxine, is administered ip to young jj Gunn rats, neuropathologic lesions that resemble human kernicterus (17) and BAEP abnormalities (18) are produced. BAEP changes include increased latencies for waves II and III, increased I-II and I-III IWI, and reduced amplitudes of waves II and III.

Observations of occasional spontaneous reversal of BAEP abnormalities induced by injecting sulfa prompted systematic studies of the reversibility of these neurophysiologic abnormalities. To create a reproducible model of reversibility, HSA was administered. HSA binds bilirubin and promotes the net transfer of bilirubin out of brain tissue (19). The partial reversal of the increased BAEP latencies after the administration of HSA $2 \mathrm{~h}$ after treatment with sulfa was previously reported (18). 
In the present study, it was hypothesized that a critical time exists beyond which neurophysiologic abnormalities become irreversible in acute bilirubin encephalopathy. In this experiment. animals received HSA 2 or $8 \mathrm{~h}$ after sulfa. The early treatment was chosen to be $2 \mathrm{~h}$ because a preliminary study showed no difference in BAEP at $8 \mathrm{~h}$ with HSA given $0,1,2$, and $4 \mathrm{~h}$ after sulfa, and the late treatment was chosen to be $8 \mathrm{~h}$ because it was hypothesized that delay of treatment past $8 \mathrm{~h}$ would produce unacceptably high mortality. BAEP were recorded before, immediately after $(0.1 \mathrm{~h})$, and $4,8,24$, and $48 \mathrm{~h}$ after injection of sulfa. The BAEP test times of $0.1,4$, and $8 \mathrm{~h}$ were chosen to correspond with the times of a previous study (18), and 24- and 48-h times were added to examine more delayed effects. A difference between treatment early $(2 \mathrm{~h})$ and later $(8 \mathrm{~h})$ after acute, sulfa-induced bilirubin toxicity was hypothesized.

\section{MATERIALS AND METHODS}

BAEP stimulus and recording. The methods have been previously described (18). Briefly, after intramuscular administration of ketamine $(60 \mathrm{mg} / \mathrm{kg})$ and acepromazine $(6 \mathrm{mg} / \mathrm{kg})$ anesthesia. platinum needle electrodes (Grass Instruments, Quincy, MA) were inserted s.c. at the vertex and over the right and left mastoid bones. Supplemental anesthesia, one quarter to one half the original dose, was given during the experiments as needed to prevent muscle activity, which was monitored continuously from the scalp electrodes. Rectal temperature was maintained between 37.0 and $37.2^{\circ} \mathrm{C}$ for $10 \mathrm{~min}$ before and during BAEP recordings. Scalp electrical activity was amplified $\times 10^{5}$, filtered from 30 to $3000 \mathrm{~Hz}$, and averaged on a Nicolet 1170 Evoked Potential Averaging System (Nicolet Instruments, Madison, WI) for 10.24 ms poststimulus. The stimuli were $100-\mu$ s clicks at $75 \mathrm{~dB}$ sound pressure level delivered at a rate of 33.5 clicks/s by a Sony Walkman 4LIS speaker centered over the right external ear canal just touching the pinna. The left ear was plugged with Audalin earmold impression material (Esschem Company, Essington, PA) to minimize stimulation of the contralateral ear. All recordings were done in a sound-attenuated booth (model AC-3, Industrial Acoustic Company, New York, NY). Each BAEP was derived from the response to 2048 clicks, replicated, and plotted separately. The two replications were then digitally added and used to obtain the latencies and amplitudes of BAEP peaks. The largest replicable peak was chosen; if there were bifid peaks, the later peak was chosen.

Experiments. To create a reproducible model of reversibility, HSA (Sigma Chemical Company, St. Louis, MO) was administered, because other therapies (e.g. exchange transfusions and phototherapy) are technically difficult in infant rats. Preliminary trials indicated that a dose of $2 \mathrm{~g} / \mathrm{kg}$ HSA diluted in $5 \%$ dextrose to a concentration of $100 \mathrm{mg} / \mathrm{mL}$ was the largest single dose that

Table 1. Baseline values of B.1EP latencies, IH'I and amplitudes in 17- to 20-d-old ij Gunn rats born to ij mothers

\begin{tabular}{llccc}
\hline & & Mean $\pm \mathrm{SD}^{*}$ & $n$ & $F \dagger$ \\
\hline Latency $(\mathrm{ms})$ & Wave I & $1.144 \pm 0.051$ & 56 & 0.159 \\
& Wave II & $2.242 \pm 0.106$ & 56 & 0.108 \\
& Wave III & $3.065 \pm 0.142$ & 56 & 0.188 \\
IWI (ms) & I-II & $1.107 \pm 0.070$ & 56 & 0.101 \\
& II-III & $0.815 \pm 0.083$ & 56 & 0.384 \\
\multirow{3}{*}{ Amplitude $(\mu \mathrm{V})$} & I-III & $1.911 \pm 0.110$ & 56 & 0.239 \\
& Wave I & $0.692 \pm 0.178$ & 56 & 1.006 \\
& Wave II & $1.293 \pm 0.332$ & 56 & 0.044 \\
& Wave III & $1.329 \pm 0.350$ & 56 & 0.999 \\
\hline
\end{tabular}

* Pretreatment mean \pm 1 SD for rats in all four groups combined.

+ One-way ANOVA $F$ value for differences between the four groups: $d f=3.52 ; 0.35<p<0.96$.
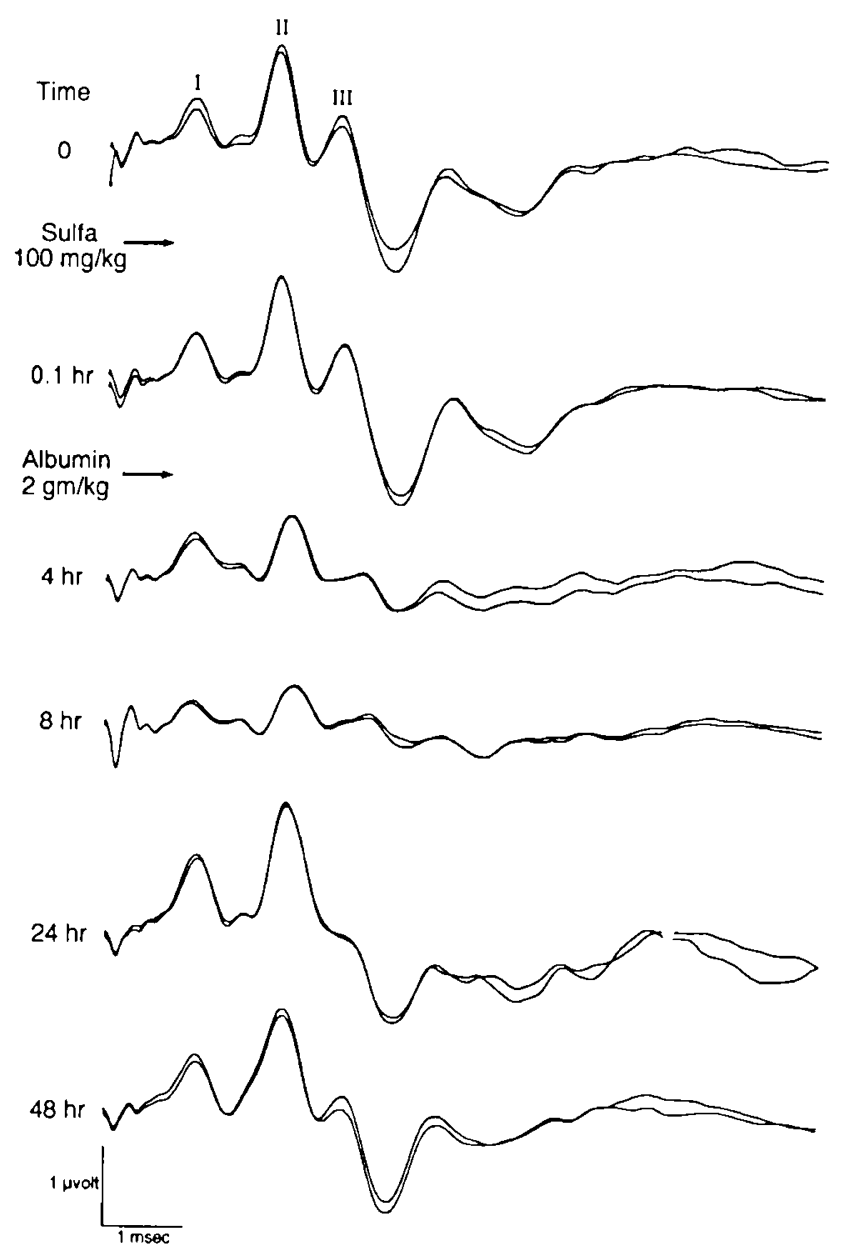

Fig. 1. BAEP in a 20-d-old jj Gunn rat before and after injection of sulfa $100 \mathrm{mg} / \mathrm{kg}$ ip to produce bilirubin toxicity and after injection of HSA $2 \mathrm{~g} / \mathrm{kg}$ ip at $2 \mathrm{~h}$ to reverse the abnormality. Note the increase in latencies of II and III (due to the increased I-II, II-III IWI) and the decrease in amplitudes of waves II and III in the BAEP recorded at 4 and $8 \mathrm{~h}$, which return to nearly normal values by 24 and $48 \mathrm{~h}$.

could be safely given ip without undue risk of respiratory embarrassment and death from fluid overload.

BAEP were recorded in 14 litters of ji rats before $(0 \mathrm{~h})$. immediately after $(0.1 \mathrm{~h})$, and $4,8,24$, and $48 \mathrm{~h}$ after injection of either sulfa $100 \mathrm{mg} / \mathrm{kg}$ ip or an equal volume of saline. Animals were 17 - to 20 -d-old jj Gunn rats $(18.4 \pm 1.34 \mathrm{~d}$, mean $\pm \mathrm{SD}$ ) from $\mathrm{jj} \times \mathrm{jj}$ matings obtained from a breeding colony maintained at the Waisman Center of the University of Wisconsin-Madison. In each litter to be used, animals were weighed and the four rats most closely matched for weight were selected and randomly assigned to one of four groups: 1) sulfa only, 2) sulfa + HSA at $2 \mathrm{~h}, 3)$ sulfa + HSA at $8 \mathrm{~h}$, or 4$)$ saline only $(n=14$ per group). HSA dose was $2 \mathrm{mg} / \mathrm{kg}$ ip. In the sulfa and saline only groups, an equal volume of $5 \%$ dextrose (the diluent for HSA) was given $2 \mathrm{~h}$ after injection.

Data analysis. The latencies of waves I, II, and III were scored, and the values were used to derive IWI of I-II (I-II IWI $=$ latency II - latency I) and II-III. For analysis, the contralateral mastoid to ipsilateral mastoid electrode montage was chosen, inasmuch as it was previously found that this montage yielded the clearest distinction between waves (15). The two replications, each the response to 2048 stimuli, were digitally added and scored with a digital cursor. The largest replicable peak was chosen; if there were bifid peaks, the later peak was chosen. Changes in BAEP latencies and IWI were calculated by subtract- 
Table 2. Between group, repeated measures ANOVA for all four groups analyzed at four times (0, 0.1. 4. and 8 h) and for three' groups (sulfa + HS a at 2 h, sulfa + IIS.1 at 8 h, and saline) analyzed at six times (previous plus 24 and 48 h)*

\begin{tabular}{|c|c|c|c|c|c|c|c|}
\hline & & \multicolumn{3}{|c|}{ Four groups: four times } & \multicolumn{3}{|c|}{ Three groups; six times } \\
\hline & & $I$ value & $d f$ & $p$ value & $F$ value & $d t$ & p) value \\
\hline \multicolumn{8}{|c|}{ Latency } \\
\hline \multirow[t]{3}{*}{ I } & Group & 0.035 & 3.51 & 0.99 & 1.5660 & 2.32 & 0.224 \\
\hline & Time & 1.809 & 3,153 & 0.15 & 7.0271 & 5.160 & $6 \times 10^{-6}$ \\
\hline & Group $\times$ time & 0.378 & 9,153 & 0.94 & 1.790 & 10.160 & 0.066 \\
\hline \multirow[t]{3}{*}{ I-II } & Group & 10.051 & 3.51 & $3 \times 10^{-6}$ & 18.296 & 2.32 & $5 \times 10^{-t}$ \\
\hline & Time & 192.74 & 3,153 & $<10^{-9}$ & 36.039 & 5.160 & $<10^{-4}$ \\
\hline & Group $\times$ time & 129.073 & 9,153 & $<10^{-9}$ & 12.396 & 10,160 & $<10^{-9}$ \\
\hline \multirow[t]{3}{*}{ II-III } & Group & 11.793 & 3.49 & $6 \times 10^{-7}$ & 14.851 & 2.26 & $5 \times 10^{-6}$ \\
\hline & Time & 155.95 & 3,147 & $<10^{-9}$ & 29.387 & 5.130 & $<10^{-9}$ \\
\hline & Group $\times$ time & 623.978 & 9.147 & $<10^{-9}$ & 10.364 & 10.130 & $<10^{-4}$ \\
\hline \multicolumn{8}{|c|}{ Amplitude } \\
\hline \multirow[t]{3}{*}{ I } & Group & 5.256 & 3.51 & 0.003 & 13.093 & 2.33 & $6 \times 10^{-5}$ \\
\hline & Time & 14.929 & 3.153 & $1 \times 10^{-x}$ & 4.835 & 5,165 & $4 \times 10^{-4}$ \\
\hline & Group $\times$ time & 6.985 & 9.153 & $2 \times 10^{-x}$ & 6.644 & 10.165 & $1 \times 10^{-x}$ \\
\hline \multirow[t]{3}{*}{ II } & Group & 15.937 & 3.51 & $2 \times 10^{-7}$ & 26.243 & 2,32 & $2 \times 10^{-8}$ \\
\hline & Time & 127.830 & 3.153 & $<10^{-9}$ & 23.070 & 5,160 & $<10^{-4}$ \\
\hline & Group $\times$ time & 26.464 & 9.153 & $<10^{-9}$ & 12.067 & 10.160 & $<10^{-4}$ \\
\hline \multirow[t]{3}{*}{ III } & Group & 15.054 & 3,43 & $8 \times 10^{-7}$ & 14.928 & 2.24 & $6 \times 10^{-5}$ \\
\hline & Time & 292.26 & 3.129 & $<10^{-9}$ & 67.730 & 5,120 & $<10^{-4}$ \\
\hline & Group $\times$ time & 34.820 & 9,129 & $<10^{-9}$ & 18.757 & 10,120 & $<10^{-4}$ \\
\hline
\end{tabular}

* The analysis was divided because of the deaths of eight of 14 and 10 of 14 animals in the sulfa-only group at 24 and 48 h, respectively.

ing baseline from subsequent values; the results were expressed as $د \mathrm{~ms}$. Amplitudes were measured on hard copy printouts from the highest peak to the subsequent trough for waves I, II, and III and converted to $\mu \mathrm{V}$ by comparison with a $0.5-\mu \mathrm{V}$ calibration standard (Nicolet model Cal-200). Amplitude changes were calculated by dividing subsequent waves by their baseline values; the results were expressed as a percent of baseline.

Statistical analyses were done by repeated measures ANOVA and Tukey HSD for specific group comparisons (Systat. Inc., Evanston, IL). We measured the latency of wave I, the I-II and II-III IWI, and the amplitudes of waves I, II, and III, a total of six dependent variables. Assuming independence, an overall experiment-wise $p$ value of 0.01 would require individual $p$ values of $\leq 0.00167(0.01 \div 6)(20)$. If these BAEP measures are not truly independent, then these criteria may be unnecessarily strict. Because of significant missing data due to the deaths of over half the animals in the sulfa-only group at 24 and $48 \mathrm{~h}$, the repeated measure ANOVA analysis of group (four levels) by time (six repeated levels) was divided into two analyses: 1 ) all four groups at the first four times $(0$ to $8 \mathrm{~h})$ before the deaths occurred, and 2) three of the groups at all six times ( 0 to $48 \mathrm{~h}$ ), excluding the group with missing data.

\section{RESULTS}

In baseline recordings, waves I, II, and III were identified in virtually all $\mathrm{jj}$ rats, and there were no statistically significant differences between the groups in baseline latencies, IWI, or amplitudes (Table 1). Recordings in one representative 20-d-old jj Gunn rat illustrate the BAEP waves obtained (Fig. 1). BAEP showed no change immediately after injection of $100 \mathrm{mg} / \mathrm{kg}$ of sulfa; at 4 and $8 \mathrm{~h}$ after sulfonamide injection, there was a prolongation of waves II and III and the I-II and II-III IWI, and a decrease of II and III amplitudes. Abnormal BAEP showed considerable recovery by 24 and $48 \mathrm{~h}$. Mortality was increased for the sulfa-only group, with eight of 14 dead versus one of 28 in sulfa + HSA groups at $24 \mathrm{~h}\left(p<0.001\right.$ by $\chi^{2}$ analysis $)$.

Repeated measures ANOVA showed significant differences between groups for the I-II IWI and wave II and III amplitudes for all four groups analyzed over the first $8 \mathrm{~h}$ and for the three groups without significant missing data analyzed over $48 \mathrm{~h}$ (Table 2). Significant effects of time and the interaction of group with time were also found at a $p<10^{-9}$ for these and other variables including II-III IWI and wave I and III amplitudes (Table 2).

BAEP latency and IIIT. Wave I latency (Fig. 2.1) showed no statistically significant changes between treatment groups or with time in the first $8 \mathrm{~h}$ but increased significantly (Table 2) with time at 24 and $48 \mathrm{~h}$ in the sulfa + HSA-treated groups.

The I-II IWI (Fig. 2B) differed significantly between the four groups after 4 and $8 \mathrm{~h}\left(p<10^{-8}\right.$ each, one-way ANOVA), increasing to $0.27 \mathrm{~ms}(21 \%)$ above baseline at $8 \mathrm{~h}$ for the two sulfa groups not receiving treatment before that time $(p)=$ 0.00016 , Tukey HSD multiple comparison test). The I-II IWI was less abnormal for the sulfa + HSA at $2 \mathrm{~h}$ group compared with the other sulfa groups at 4 and $8 \mathrm{~h}$ (each $p=0.02$. Tukey HSD) and recovered at 24 and $48 \mathrm{~h}$ for both HSA-treated groups compared with their 8 -h peak (each $p=0.0001$ ). However, at 48 h, I-II IWI did not return to baseline and was still 0.09 and 0.105 ms greater in the HSA at $2 \mathrm{~h}$ and HSA at $8 \mathrm{~h}$ groups, respectively, than in the saline controls $(p=0.002$ and 0.0016 , respectively, Tukey HSD). Similar changes were found in the II-III IWI (Fig. $2 C$ ) except that no differences between the three sulfa-treated groups could be discerned in the first $8 \mathrm{~h}$. There were no statistically significant differences between the two sulfonamidetreated groups given HSA.

BAEP amplitudes. There were significant differences in wave I amplitudes between groups, with time, and for the interaction of group and time (Fig. $3 A$, Table 2). Significant group by time interactions between the two sulfa + HSA groups (Table 3) demonstrate a beneficial effect of earlier HSA treatment on wave I amplitude.

There were highly significant differences in wave II amplitude due to reduction in amplitude for all the sulfa-injected groups (Fig. $3 B$ ). The wave II amplitude of the two groups given sulfa not receiving treatment was $25 \pm 9 \%$ of baseline, compared with $43 \pm 18 \%$ for the sulfa group given HSA for $2 \mathrm{~h}(p)=0.01$, Tukey HSD) and $115 \pm 28 \%$ for the saline group. Wave II amplitude improved in the two HSA groups and was not significantly different than baseline values or saline controls at 

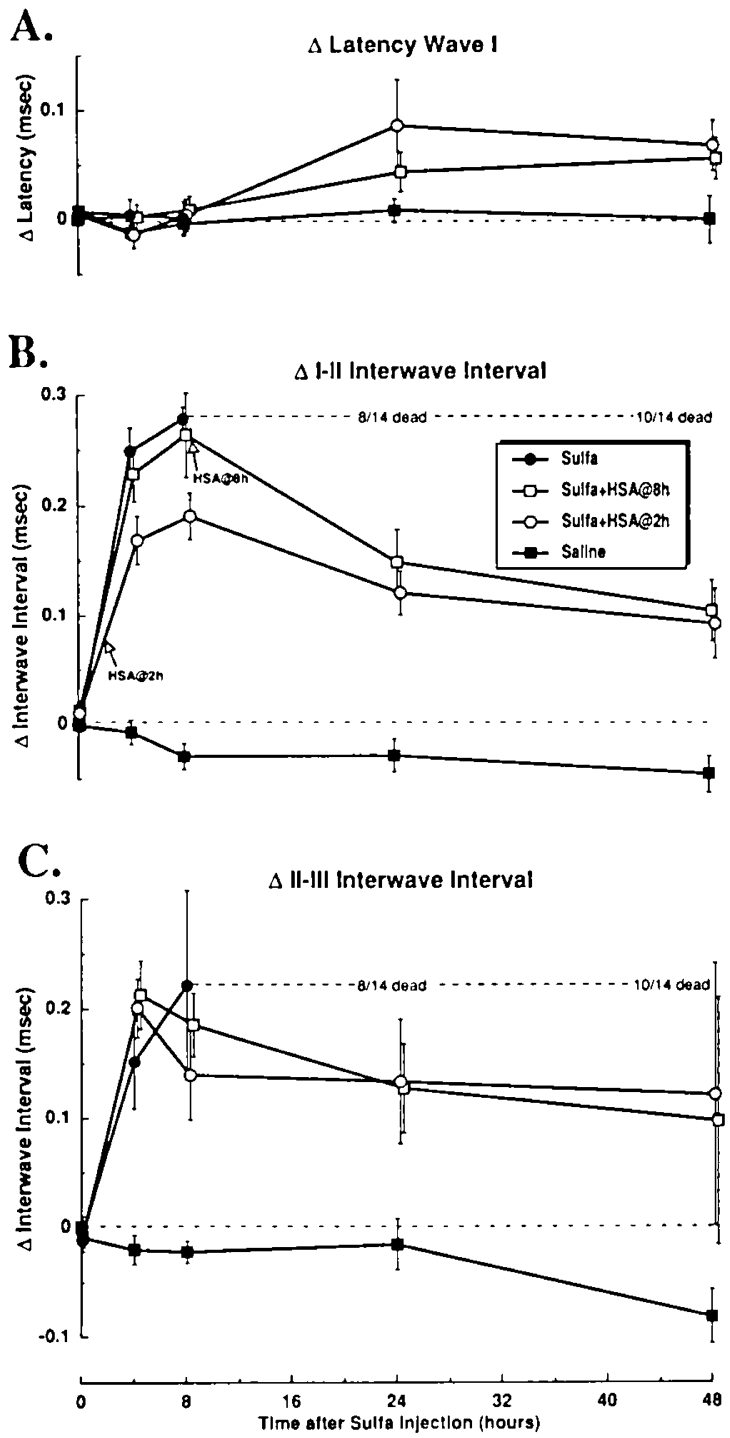

Fig. 2. Change of wave I latency and I-II and II-III IWI (mean \pm SEM) in jj Gunn rats given $100 \mathrm{mg} / \mathrm{kg}$ sulfa alone (๑), sulfa followed by $2 \mathrm{~g} / \mathrm{kg}$ HSA $2 \mathrm{~h}(O)$ or $8 \mathrm{~h}(\square)$ after sulfa, and saline alone $(\square) . A$, Change of wave I latency. There was no significant difference between groups at 4 and $8 \mathrm{~h}$, but wave I latency increased at both 24 and $48 \mathrm{~h}$. The majority of animals given sulfa alone and not treated with HSA were dead at 24 h. $B$, Change of I-II IWI. Note the I-II increase in all groups given sulfa compared with the saline controls. However, at $8 \mathrm{~h}$ after sulfa, the group given HSA at 2 h showed less severe abnormality than the two groups not given HSA before $8 \mathrm{~h}$. Differences at $8 \mathrm{~h}$ between the two groups given HSA are no longer apparent at 24 and $48 \mathrm{~h}$. $C$, Change of II-III IWI. Note the II-III increase in all groups given sulfa compared with the saline controls and partial recovery at 24 and $48 \mathrm{~h}$ in both sulfa groups receiving HSA. There were no significant differences between groups given HSA at 2 is $8 \mathrm{~h}$ after sulfa.

$48 \mathrm{~h}$.

Wave III (Fig. $3 C$ ) similarly declined to $9.3 \pm 8.7 \%$ of baseline in the groups treated with only sulfa for $\leq 8 \mathrm{~h}$. There was no evidence of protection of wave III amplitude by early HSA treatment and little recovery at 24 and $48 \mathrm{~h}$.

\section{DISCUSSION}

The baseline values for these $\mathrm{jj}$ rats are similar to those reported previously (12). Prolongation of the I-II and I-III IWI and dete-
A.

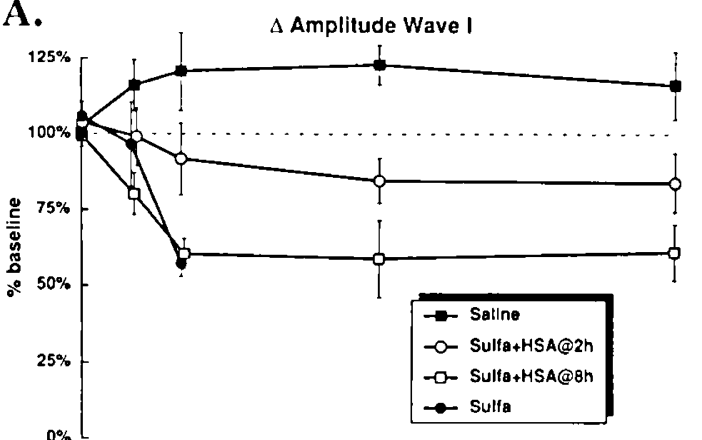

B.

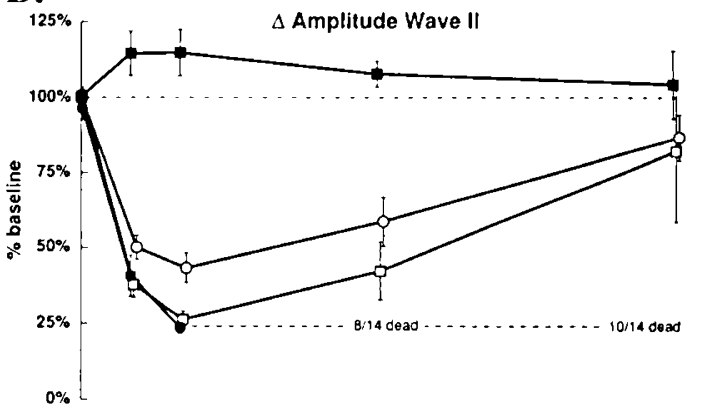

C.

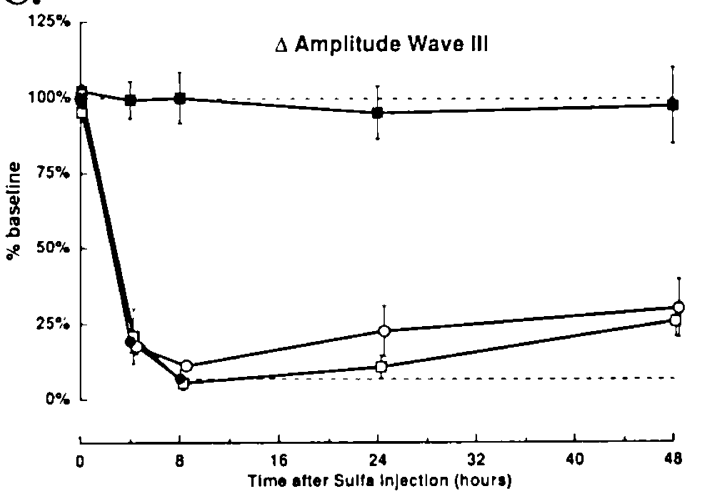

Fig. 3. Change of amplitude of waves I, II, and III (mean \pm SEM) in jj Gunn rats given $100 \mathrm{mg} / \mathrm{kg}$ sulfa alone (๑), sulfa followed by $2 \mathrm{~g} / \mathrm{kg}$ HSA 2 h $(O)$ or $8 \mathrm{~h}(\square)$ after sulfa, and saline alone (ם). A, BAEP wave I amplitude compared with baseline. Note the decrease in amplitude of wave $I$ in animals given sulfa and the partial protection with carly (2-h) HSA treatment. $B$, Change in amplitude of wave II. Wave II amplitude decreased in all sulfa-treated groups, and the group treated with HSA at $2 \mathrm{~h}$ had less of a decrease in amplitude than either those treated at $8 \mathrm{~h}$ or those not treated with sulfa. Note the recovery of wave II amplitude in both HSA-treated groups. C. Change in amplitude of wave III in saline- and sulfa-treated $\mathrm{jj}$ Gunn rats compared with baseline. Note the decrease in wave III amplitude for all sulfa-treated groups with no recovery after HSA administration at either 2 or $8 \mathrm{~h}$ after sulfa.

rioration of amplitudes of BAEP waves II and III were seen 4 and $8 \mathrm{~h}$ after sulfonamide injection as previously shown (18). In addition, there were changes in wave I and the II-III IWI in jj rats given sulfonamide. These additional abnormalities may have resulted from a greater power to detect differences with the larger sample size of this study or from a difference in our Gunn rat colony over time, resulting in rats with greater serum bilirubin levels at the start of the study and therefore more bilirubin available to be displaced into brain tissue.

These studies show that some of the neurophysiologic abnormalities occurring after sulfa-induced bilirubin toxicity are re- 
Table 3. Between group, repeated measures ANOVA for the wo groups given sulfa and then treated with IISA at 2 and $8 \mathrm{~h}$ analyzed at six times from 0 to $48 \mathrm{~h}$

\begin{tabular}{clrll}
\hline & & $F$ value & $d f$ & $p$ value \\
\hline Latency & & & & \\
I & Group & 1.314 & 1,21 & 0.265 \\
& Time & 7.304 & 5.105 & $7 \times 10^{-6}$ \\
I-II & Group $\times$ time & 0.931 & 5.105 & 0.464 \\
& Group & 1.243 & 1,21 & 0.277 \\
& Time & 43.388 & 5.105 & $1 \times 10^{-9}$ \\
II-III & Group $\times$ time & 0.656 & 5,105 & 0.658 \\
& Group & 0.667 & 1,15 & 0.427 \\
& Time & 27.070 & 5.75 & $10^{-9}$ \\
Amplitude & Group $\times$ time & 0.241 & 5.75 & 0.943 \\
I & & & & \\
& Group & 0.165 & 1,21 & 0.689 \\
& Time & 12.364 & 5.105 & $2 \times 10^{-9}$ \\
II & Group $\times$ time & 3.286 & 5,105 & 0.0085 \\
& Group & 0.925 & 1.20 & 0.348 \\
& Time & 40.140 & 5.100 & $<10^{-9}$ \\
III & Group $\times$ time & 1.492 & 5.100 & 0.199 \\
& Group & 0.006 & 1.12 & 0.941 \\
& Time & 96.155 & 5.60 & $<10^{-9}$ \\
& Group $\times$ time & 1.834 & 5.60 & 0.120 \\
\hline
\end{tabular}

versible with treatment given up to $8 \mathrm{~h}$ later. Most BAEP variables reached maximum abnormality at $8 \mathrm{~h}$, and some, $\mathcal{c} . g$. wave II amplitude, recovered completely; some, e.g. I-II and IIIII IWI, recovered partially; and some, e.g. amplitude of waves I and III, did not recover at all.

Wave I latency was not affected at 4 or $8 \mathrm{~h}$ but became abnormal at 24 and $48 \mathrm{~h}$ after sulfonamide, despite HSA treatment. Wave I amplitude decrease was partially protected by early treatment with HSA, an effect that persisted. This may indicate a different pathogenesis of bilirubin toxicity on the peripheral auditory system, the auditory nerve in this case, versus the central auditory system.

Therapeutic intervention with HSA as late as $8 \mathrm{~h}$ after acute bilirubin encephalopathy promoted recovery of neurophysiologic function as effectively as intervention at $2 \mathrm{~h}$. Although there was a tendency in the group given earlier treatment with HSA for more apparent recovery at $24 \mathrm{~h}$ with some measures, e.g. wave II amplitude or I-II IWI, statistically significant differences between early and late HSA treatment were generally not seen at $48 \mathrm{~h}$. This indicates that the hypothesized "critical period" for recovery of auditory brainstem function after acute bilirubin neurotoxicity may extend beyond $8 \mathrm{~h}$.

Total recovery was seen occasionally in $\mathrm{jj}$ rats given sulfonamide. Partial recovery of abnormal BAEP was seen for most treated animals, but total recovery was seen only in wave II amplitude.

The BAEP abnormalities produced by giving sulfa to jj Gunn rats are likely to be due to the net transfer of bilirubin from the blood into brain tissue (19). Occasionally after injection with sulfa, BAEP abnormalities in jj rats spontaneously reverse, perhaps due to the excretion of the sulfonamide and the transfer of bilirubin from brain tissue back to the circulation. Bilirubin neurotoxicity may be reversible for a limited time, and after this time bilirubin toxicity may produce permanent damage either by poisoning the metabolic machinery of neurons long enough for metabolic damage to become irreversible or by becoming irreversibly bound to brain tissue.

Although we demonstrated reversibility of BAEP, these responses do not fully recover and thus some irreversible damage may have occurred. However, the period of follow-up was only $48 \mathrm{~h}$ in these studies. A longer follow-up period may have allowed more time for recovery.

These studies indicate that bilirubin-induced neurophysiologic dysfunction is at least partially reversible. The phenomenon occurs spontaneously in a minority of $\mathrm{jj}$ animals given sulfa and occurs more consistently when HSA is given to promote the net transfer of bilirubin out of brain tissue. These experiments indicate that BAEP of $\mathrm{jj}$ Gunn rats given sulfa may be used to study functional recovery of the CNS after bilirubin toxicity.

Acknowledgments. The author thanks Drs. Kurt Hecox and Gregory Heard for their helpful comments on the manuscript and Kathy T. Potter for her expert technical assistance in the planning and data collection for this project.

\section{REFERENCES}

1. Volpe JJ 1987 Bilirubin and brain injury. In: Volpe JJ (eds) Neurology of the Newborn. WB Saunders Co., Philadelphia. pp 336-356

2. Lenhardt ML, McArtor R. Bryant B 1984 Effects of neonatal hyperbilirubinemia on the brainstem electrical response. J Pediatr 104:281-284

3. Nakamura H, Takada S. Shimabuku R. Matsuo M. Matsuo T. Nagishi H 1984 Auditory nerve and brainstem responses in newborn infants with hyperbilirubinemia. Pediatrics 75:703-708

4. Nwaesei CG, Van Aerde J, Boyden M. Perlman M 1984 Changes in auditory brainstem responses in hyperbilirubinemic infants before and after exchange transfusion. Pediatrics 74:800-803

5. Perlman M. Fainmesser P. Sohmer H, Tamari H, Wax Y. Pevsmer B 1983 Auditory nerve-brainstem evoked responses in hyperbilirubinemic neonates. Pediatrics 72:658-664

6. Wennberg RP, Ahlfors LE, Bickers R 1982 Abnormal auditory brainstem response in a newborn infant with hyperbilirubinemia: improvement with exchange transfusion. J Pediatr 100:624

7. Johnson L. Sarmiento F, Blanc WA, Day R 1959 kernicterus in rats with an inherited deficiency of glucuronyl transferase. Am J Dis Child 97:591-608

8. Strebel L, Odelt GB 197! Bilirubin uridine disphosphoglucuronyltransferase in rat liver microsomes: genetic variation and maturation. Pediatr Res 5:548-
559

9. Ahdab-Barmada M. Moossy J 1984 The neuropathology of kernicterus in the premature neonate: diagnostic problems. J Neuropathol Exp Neurol 43:4556

10. Swenson RM. Jew JY 1982 Learning deficits and brain monoamines in rats with congenital hyperbilirubinemia. Exp Neurol 76:447-456

11. Schutta HS, Johnson L 1969 Clinical signs and morphologic abnormalities in Gunn rats treated with sulfadimethoxine. J Pediatr 75:1070-1079

12. Shapiro SM. Hecox KE 1988 Developmental studies of brainstem auditory evoked potentials in jaundiced Gunn rats. Dev Brain Res 41:147-157

13. Shapiro SM 1991 Binaural effects in brainstem auditory evoked potentials of jaundiced rats. Hearing Res 53:41-48

14. Shapiro SM. Conlec JW 1991 Brainstem auditory evoked potentials correlate with morphological changes in Gunn rat pups. Hearing Res 57:16-22

15. Shapiro SM, Hecox KE 1989 Brain stem auditory evoked potentials in jaundiced Gunn rats. Ann Otol Rhinol Laryngol 98:308-317

16. Odell GB 1959 The dissociation of bilirubin from albumin and its clinical implications. J Pediatr 55:268-279

17. Rose AL, Wisniewski H 1979 Acute bilirubin encephalopathy induced with sulfadimethoxine in Gunn rats. J Neuropathol Exp Neurol 38:152-164

18. Shapiro SM 1988 Acute brainstem auditory evoked potential abnormalities in jaundiced Gunn rats given sulfonamide. Pediatr Res 23:306-310

19 Diamond I, Schmid R 1966 Experimental bilirubin encephalopathy: the mode of entry of bilirubin $-{ }^{14} \mathrm{C}$ into the CNS. J Clin Invest 45:678-689

20. Keppel G 1982 Design and Analysis: A Researcher's Handbook. Prentice-Hall. Englewood Cliffs, NJ 